\title{
Effects of Lying Position on P-Wave Dispersion in Patients with Heart Failure
}

\author{
Muhammed Oylumlu ${ }^{a}$ Adnan Dogan ${ }^{a}$ Orhan Ozer ${ }^{b}$ Murat Yuce ${ }^{b}$ \\ Suleyman Ercan ${ }^{\mathrm{b}}$ Vedat Davutoglu ${ }^{\mathrm{b}}$ \\ ${ }^{a}$ Department of Cardiology, Dumlupinar University School of Medicine, Kutahya, and bepartment of \\ Cardiology, Gaziantep University School of Medicine, Gaziantep, Turkey
}

\section{Key Words}

Heart failure $\cdot$ P-wave dispersion $\cdot$ Lying position .

Atrial fibrillation

\begin{abstract}
Objective: It was the aim of this study to investigate the effects of the right lateral decubitus, left lateral decubitus and supine lying position on P-wave dispersion (PWD) in patients with heart failure (HF). Subjects and Methods: Seventeen patients with $\mathrm{HF}$ whose ejection fraction was $<35 \%$ were included in the study. Right lateral decubitus, left lateral decubitus and supine electrocardiogram (ECG) recordings were obtained. The recordings for each of the three positions were taken after the patients had maintained each position for $30 \mathrm{~min}$ to ensure a stabilized hemodynamic position. For the baseline recording, in supine position, there was no 30min waiting period before the ECG. Results: After the right lateral decubitus position, there was a statistically significant reduction in the longest $P$-wave duration (100.0 \pm 14.5 and $84.7 \pm 16.2 \mathrm{~ms} ; \mathrm{p}=0.001)$ and a significant decrease in PWD $(41.7 \pm 8.0$ and $24.1 \pm 7.1 \mathrm{~ms} ; \mathrm{p}<0.0001)$. After the left lateral decubitus position, there was no significant change between the baseline PWD values $(41.7 \pm 8.0$ and $40.2 \pm 9.7 \mathrm{~ms}$; $p=0.606)$. After the supine position, there was no significant
\end{abstract}

change between the baseline PWD values ( $41.7 \pm 8.0$ and $39.7 \pm 9.4 \mathrm{~ms} ; p=0.427)$. Conclusion: Our study revealed that patients' PWDs and maximum P-wave durations were lower in the right lateral decubitus lying position than in other positions. The clinical implication of this study needs to be further explored.

(c) 2014 S. Karger AG, Basel

\section{Introduction}

Heart failure (HF) is one of today's major health problems, with increasing prevalence [1]. In patients hospitalized for decompensated HF, new arrhythmias result in prolonged hospital stay as well as in increased mortality and morbidity rates and are an economic burden [2]. Despite the advances in treatment, HF continues to be an important health problem due to its high mortality and morbidity rates.

During the course of the disease, neuroendocrine and circulatory maladaptation processes cause structural, contractile and electrical restructuring in the heart tissue. As a result of this restructuring, atrial fibrillation (AF) develops in association with reentry centers in the atria and has adverse effects on the prognosis of the disease and

\begin{tabular}{ll}
\hline KARGER & $\begin{array}{l}\text { @ 2014 S. Karger AG, Basel } \\
1011-7571 / 14 / 0236-0556 \$ 39.50 / 0 \quad \text { Karger }\end{array}$ \\
E-Mail karger@karger.com & $\begin{array}{l}\text { Thisis an Open Access article licensed under the terms of the } \\
\text { Creative Commons Attribution-NonCommercial 3.0 Un- } \\
\text { ported license (CC BY-NC) (www.karger.com/OA-license), } \\
\text { applicable to the online version of the article only. Distribu- } \\
\text { tion permitted for non-commercial purposes only. }\end{array}$
\end{tabular}

Muhammed Oylumlu, MD

Department of Cardiology

Dumlupinar University School of Medicine

TR-43020 Kutahya (Turkey)

E-Mail muhammedoylumlu@yahoo.com 
the patient's functional capacity. AF is the most common arrhythmia in these patients and it develops due to left atrial dilatation because of increased intra-arterial pressure as well as due to the change in the geometry of myofibrils and nonhomogeneous atrial fibrosis. AF also significantly increases the patient's hemodynamic and thromboembolic complications and if the sinus rhythm is not restored, it continues to be the basic rhythm of the patient [3].

$\mathrm{P}$-wave dispersion (PWD), as an important predictor of AF, is accepted as a noninvasive and easy-to-use method [4]. Surface electrocardiogram (ECG) is the most common noninvasive method for cardiovascular assessment. PWD is the reflection of this abnormal pattern on a 12lead ECG and can be described as the difference between the longest (P-longest) and the shortest (P-shortest) Pwave duration. PWD is a measure of heterogeneity of atrial refractoriness, and prolonged PWD illustrates intra- and interatrial nonuniform conduction [5]. Prolonged PWD has been reported to be an independent risk factor for the development of AF [6].

In patients with $\mathrm{HF}$, posture significantly affects the activity of the autonomic nervous system $[7,8]$. In the right lateral decubitus position, sympathetic tone is reduced while parasympathetic activity increases. Therefore, this is the preferred lying position for patients with HF. An impact of body position habitus on PWD is un- known. The present study aimed to investigate if different lying positions, such as the right lateral decubitus, left lateral decubitus and supine position, have an effect on PWD in patients with HF.

\section{Subjects and Methods}

\section{Study Population}

Seventeen patients (8 males and 9 females) at the Cardiology Clinic of Gaziantep University School of Medicine Hospital were included in the study. They were diagnosed with HF and hospitalized for low left ventricular ejection fraction $(<35 \%)$. Seven patients had a diagnosis of ischemic cardiomyopathy while the diagnosis of the remaining was nonischemic cardiomyopathy. Exclusion criteria were patients with chronic obstructive pulmonary disease, significant valvular heart disease, thyrotoxicosis, hypothyroidism, chronic kidney and liver diseases, malignancy, and anemia (hemoglobin $<10 \mathrm{~g} / \mathrm{dl}$ ). Electrocardiographic recordings were conducted after the patients were hemodynamically stable. The recordings were taken in the morning after a whole night without drinking to mitigate the circadian variation of the cardiac autonomic nervous activity. Baseline ECG recordings were obtained first, followed by the right lateral decubitus, left lateral decubitus and supine ECG recordings. The recordings were conducted at 50 $\mathrm{mm} / \mathrm{s}$ for all patients. The 12-lead ECG recordings for each of the three positions were taken after the patients had lain down in each position for $30 \mathrm{~min}$ to ensure a stabilized hemodynamic milieu. The number of patients in the study group using drugs are as follows: diuretics (7), angiotensin-converting enzyme inhibitor (11), angiotensin receptor blocker (6), $\beta$-blocker drugs (17), nitrate (3),
Fig. 1. ECG showing P-longest in different lying positions: baseline measurement (a), after the right lateral decubitus position (b), after the left lateral decubitus position (c), and after the supine position (d). It should be noted that this ECG was recorded at $50 \mathrm{~mm} / \mathrm{s}$.
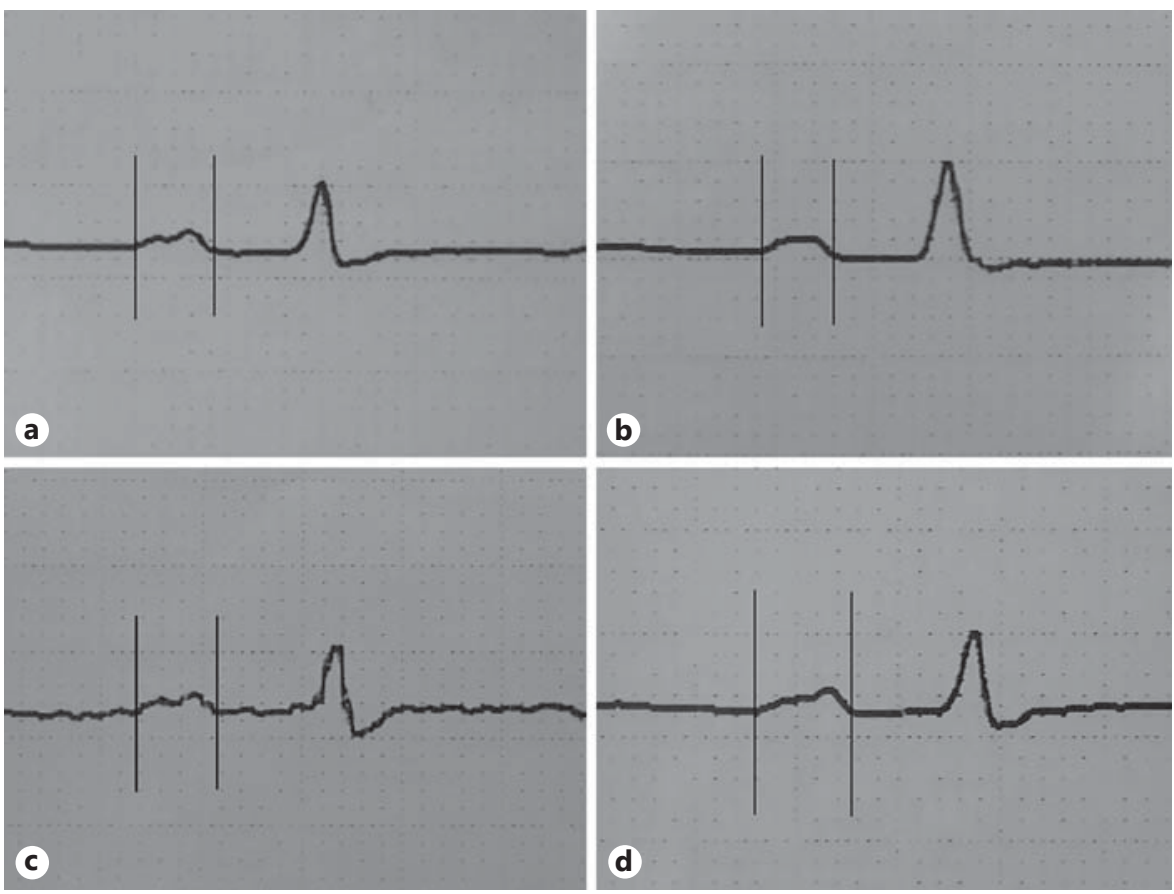
and acetylsalicylic acid (10). None of the patients used antiarrhythmic drugs. This study was approved by the Ethics Committee of the Gaziantep University.

\section{Measurement of PWD}

Patients' 12-lead surface ECGs were obtained using a Schiller ECG device (Schiller AG, Baar, Switzerland). ECG recordings were done at the speed of $50 \mathrm{~mm} / \mathrm{s}$ and an amplitude of $1 \mathrm{mV} / \mathrm{cm}$. During recordings, patients were allowed to breathe regularly but not allowed to hold their breath and speak. To reduce the risk of error, measurements were performed manually using a ruler and a magnifying glass by two independent observers (M.O., V.D.) who were uninformed of the patients' clinical situation and postural position. The beginning of the first $\mathrm{P}$ wave was taken at its earliest departure of $\mathrm{P}$-wave deflection from the zero isoelectric line, and the end was taken at the intersection point with the PR segment (fig. 1). Baseline values of P-longest and P-shortest as well as PWDs were measured by ECG. The measurements were compared with the values for the other lying positions. The baseline position was defined as the supine lying position when the first ECG was taken, previously to the three lying positions. Its difference from the supine position was that there was no 30 -min waiting time before the ECG.

\section{Statistical Analysis}

Statistical Package for Social Sciences version 16.0 was used for data analysis, and the output was expressed as the mean \pm standard deviation. Baseline position parameters and those after the three lying positions were evaluated with the Wilcoxon test. The relationship between these parameters was examined with Spearman's correlation test. A $\kappa$ test analysis was done for intraobserver variability ( $\kappa$ test $=66 \%$ ). A p value $<0.05$ was considered statistically significant in all statistical analyses.

\section{Results}

The mean age of the patients was $68 \pm 10.2$ years (range 44-78). The demographic, clinical and echocardiographic characteristics of the patients are given in table 1. After the right lateral decubitus position, there was a statistically significant reduction in P-longest $(100.0 \pm 14.5$ and $84.7 \pm 16.2 \mathrm{~ms} ; \mathrm{p}=0.001)$; moreover, there was a signifi- cant decrease in PWD $(41.7 \pm 8.0$ and $24.1 \pm 7.1 \mathrm{~ms} ; \mathrm{p}<$ $0.0001)$. No significant change was observed in P-shortest (table 2). After the left lateral decubitus position, there was no significant change between the baseline values of P-longest, P-shortest and PWD, respectively (table 2). Similarly, after the supine position, there was no significant change between the baseline values of P-longest, $\mathrm{P}$ shortest and PWD, respectively (table 2).

Table 1. Demographic and clinical characteristics of the patients
Age, years

BMI

Pulse, bpm

Blood pressure, $\mathrm{mm} \mathrm{Hg}$

Systolic

Diastolic

Glucose, mg/dl

Urea, mg/dl

Creatine, $\mathrm{mg} / \mathrm{dl}$

Sodium, mmol/1

Potassium, $\mathrm{mmol} / \mathrm{l}$

Triglycerides, mg/dl

Total cholesterol, mg/dl

HDL, mg/dl

LDL, mg/dl

Diabetes mellitus, $\mathrm{n}$

Smoking, $\mathrm{n}$

Hypertension, $\mathrm{n}$

CHD, n

Male, $\mathrm{n}$

Female, $\mathrm{n}$

LA diameter, $\mathrm{mm}$

$\mathrm{EF}, \%$
$68(44-78)$

$26.5 \pm 4.0$

$75.4 \pm 11.2$

$119.7 \pm 23.7$

$70.3 \pm 13.7$

$128.5 \pm 52.6$

$45.1 \pm 13.6$

$0.9 \pm 0.2$

$137.5 \pm 2.0$

$4.3 \pm 0.5$

$143.0 \pm 65.1$

$183.5 \pm 53.6$

$34.0 \pm 6.5$

$119.3 \pm 37.9$

8

6

9

7

8

9

$43.3 \pm 4.8$

$28.0 \pm 5.7$
Figures in parenthesis indicate the range. BMI = Body mass index; HDL = high-density lipoprotein; LDL = low-density lipoprotein; $\mathrm{CHD}=$ coronary heart disease; $\mathrm{LA}=$ left atrium; $\mathrm{EF}=$ ejection fraction.
Table 2. Evaluation of ECG parameters based on the patients' lying position

\begin{tabular}{lcllll}
\hline & Baseline & $\begin{array}{l}\text { Right lateral } \\
\text { decubitus }\end{array}$ & $\begin{array}{l}\text { Left lateral } \\
\text { decubitus }\end{array}$ & Supine & p value \\
\hline P-longest, ms & $100.0 \pm 14.5$ & $84.7 \pm 16.2$ & $98.2 \pm 15.9$ & $98.8 \pm 16.5$ & $0.001^{\text {a }}$ \\
P-shortest, ms & $58.2 \pm 12.3$ & $60.5 \pm 11.9$ & $57.9 \pm 11.3$ & $59.4 \pm 11.9$ & $>0.05$ \\
PWD, ms & $41.7 \pm 8.0$ & $24.1 \pm 7.1$ & $40.2 \pm 9.7$ & $39.7 \pm 9.4$ & $<0.0001^{\text {b }}$ \\
Heart rate, bpm & $75.4 \pm 11.2$ & $75.7 \pm 11.7$ & $73.8 \pm 12.1$ & $74.5 \pm 11.7$ & $>0.05$ \\
\hline
\end{tabular}

a Statistical relationship between the right lateral decubitus position and baseline values of P-longest. ${ }^{b}$ Statistical relationship between the right lateral decubitus position and baseline values of PWD. 
Correlation analysis revealed that there was a negative correlation between the serum potassium value and $\mathrm{P}$ longest $(\mathrm{p}=0.036, \mathrm{r}=-0.51)$. However, the PWD and Plongest values did not prove to be statistically related $(\mathrm{p}>$ 0.05).

\section{Discussion}

These findings showed that PWD in patients with HF decreased in the right lateral decubitus position and that the values of PWD in the right lateral decubitus position were statistically lower than those in the other two positions and at baseline.

The relationship between P-wave duration and inhomogeneous and discontinuous propagation of sinus impulses has been recorded in the literature. Aytemir et al. [9] stated that there is an increased risk of AF in patients with prolonged $\mathrm{P}$-wave duration and increased PWD. Atrial tissue heterogeneity is the most important mechanism for the emergence of AF [10]. A heterogeneous prolonged refractory period and conduction velocity in atrial tissue as well as the tissue characteristics of forming a single-sided block facilitate the development of AF. In tissue with these features, fragmented atrial beats lead to the formation of micro-reentry rings and cause dozens of high-speed AF foci. PWD is an indirect display of intraand interatrial nonuniform conduction [11, 12]. Many researchers have demonstrated the relationship between the development of AF and prolonged PWD $[13,14]$. It was also reported that prolonged PWD predicts the development of AF, with a sensitivity of $83 \%$ and a specificity of $85 \%$ [5].

Fatigue and dyspnea as well as exercise intolerance and a poor prognosis are common symptoms among patients with HF. Since most HF patients have orthopnea, their preferred sleep position is the lateral decubitus position. However, there is no consensus about these patients' preference between the right and the left lateral decubitus position. Several mechanisms might be responsible for the enhancement of vagal modulation and the suppression of sympathetic modulation when in the right lateral decubitus position (the heart is located in a higher position, making the pumping of blood easier; the lower positioning of the right atrium in the right lateral decubitus position facilitates greater venous return, resulting in greater cardiac output). The right lateral decubitus position was found to have the highest vagal enhancing effect in young healthy subjects. The views on increased vagal modulation in the right lateral decubitus position and on low sympathetic modulation mechanism are as follows: the right atrium on the right side of the chest is inferior to the heart in the right lateral decubitus position, and this situation results in an increase in the amount of blood returning to the heart. Wall tension of the atrium increases due to the increased venous return, and consequently, the plasma atrial natriuretic peptide level rises. Similarly, in the right lateral decubitus position, cardiac output increases due to the increased left ventricular preload. As a result of high blood pressure, a reduction in plasma norepinephrine levels is observed because of decreased aortic baroreceptor stimulation [15].

The autonomic tone was found to be affected by Pwave duration and PWD [16]. Patients with dilated cardiomyopathy were reported to have increased sympathetic activity [17]. In one study, increased sympathetic activity was shown to result in a substantial increase in PWD [18]. Furthermore, it was also reported that patients with dilated cardiomyopathy had increased maximum P-wave durations and PWDs when compared to healthy control subjects [19].

The limitations of this study include manual measurement and a small number of patients.

\section{Conclusion}

Our study of patients with HF showed that the lying position had an effect on P-wave duration and PWD on the ECG. In the right lateral decubitus position, it was found that patients' PWDs and maximum P-wave durations were relatively lower. Future studies are warranted to determine the impact of the right lateral decubitus position on the incidence of AF in patients with HF.

References 
6 Li Z, Hertervig E, Carlson J, et al: Dispersion of refractoriness in patients with paroxysmal atrial fibrillation. J Electrocardiol 2002;35: 227-334.

$>7$ Fujita M, Miyamoto S, Sekiguchi H, et al: Effects of posture on sympathetic nervous modulation in patients with chronic heart failure. Lancet 2000;356:1822-1823.

8 Miyamoto S, Fujita M, Sekiguchi H, et al: Effects of posture on cardiac autonomic nervous activity in patients with congestive heart failure. J Am Coll Cardiol 2001;37:17881793.

$>9$ Aytemir K, Ozer N, Atalar E, et al: P-wave dispersion on 12-lead electrocardiography in patients with paroxysmal atrial fibrillation. Pacing Clin Electrophysiol 2000;23:1109-1112.

10 Ozmen N, Cebeci BS, Kardesoglu E, et al: Relationship between $\mathrm{P}$-wave dispersion and effective hemodialysis in chronic hemodialysis patients. Med Princ Pract 2007;16:147-150.
11 Sari I, Davutoglu V, Ozbala B, et al: Acute sleep deprivation is associated with increased electrocardiographic $\mathrm{P}$-wave dispersion in healthy young men and women. Pacing Clin Electrophysiol 2008;31:438-442.

12 Ercan S, Oylumlu M, Oylumlu M, et al: Kalpyetersizliği hastalarında glikoz-insülinpotasyum infüzyonunun $\mathrm{p}$ dalga dispersiyonu üzerine etkisi. Gaziantep Tip Dergisi Gaziantep Med J 2012;18:85-89.

13 Tukek T, Akkaya V, Atilgan D, et al: Effect of left atrial size and function on $\mathrm{P}$-wave dispersion: a study in patients with paroxysmal atrial fibrillation. Clin Cardiol 2001;24:676-680.

14 Andrikopolous GK, Dilaveris PE, Richter DJ, et al: Increased variance of $\mathrm{P}$-wave duration on the electrocardiogram distinguishes patients with idiopathic paroxysmal atrial fibrillation. Pacing Clin Electrophysiol 2000;23: 1127-1132.
15 Miyamoto S, Tambara K, Tamaki SI, et al: Effects of right lateral decubitus position on plasma norepinephrine and plasma atrial natriuretic peptide levels in patients with chronic congestive heart failure. Am J Cardiol 2002; 89:240-242.

16 Coumel P: Paroxysmal atrial fibrillation: a disorder of autonomic tone? Eur Heart J 1994; 15:9-16.

17 Francis GS, McDonald KM, Cohn JN: Neurohumoral activation in preclinical heart failure. Circulation 1993;87:90-96.

18 Tukek T, Akkaya V, Demirel S, et al: Effect of Valsalva maneuver on surface electrocardiographic $\mathrm{P}$-wave dispersion in paroxysmal atrial fibrillation. Am J Cardiol 2000;85:896899.

19 Senen K, Turhan H, Riza Erbay A, et al: Pwave duration and $\mathrm{P}$-wave dispersion in patients with dilated cardiomyopathy. Eur J Heart Fail 2004;6:567-569. 